Data-driven supply chain orientation and financial performance: The moderating effect of innovation focused complementary assets

\author{
Wantao Yu \\ Roehampton Business School \\ University of Roehampton \\ London SW15 5SL, UK \\ Email: wantao.yu@ roehampton.ac.uk \\ Tel.: +44(0)2083927398 \\ Mark A. Jacobs \\ Department of Operations Management, College of Business \\ University of Dayton, 300 College Park \\ Dayton, OH 45469, United States \\ Email:majacobs@udayton.edu \\ Tel: +1 9372292204 \\ Roberto Chavez \\ Facultad de Economía y Empresa \\ Universidad Diego Portales \\ Avda. Santa Clara 797 \\ Huechuraba, Santiago, Chile \\ Email: roberto.chavez@udp.cl \\ Tel: +56 222130131

\section{Mengying Feng*} \\ School of Economics and Management \\ Chongqing Jiaotong University \\ Xufu Dadao, Nanan District \\ Chongqing, China \\ Email: fengmengying@cqjtu.edu.cn \\ Tel.: +86 2386079717
}

* Corresponding author 
Wantao Yu is a professor of Supply Chain Management at the University of Roehampton. His research interests include supply chain integration, integrated green supply chain management, and retail operations and logistics. His work has been published in journals such as International Journal of Operations \& Production Management, International Journal of Production Economics, International Journal of Production Research, Industrial Marketing Management, Production Planning \& Control, Supply Chain Management: An International Journal, and Decision Support Systems.

Mark A. Jacobs is presently an associate professor of Operations and Supply Management at the University of Dayton where he teaches graduate and undergraduate courses. He has published several articles on the topics of product and portfolio complexity, modularity, and supply chain integration in the Journal of Operations Management, Journal of Product Innovation Management, and others. Prior to an academic career, Jacobs held a variety of positions of increasing responsibility in the professional services industry.

Roberto Chavez is presently an assistant professor of Operations and Supply Chain Management at the Universidad Diego Portales, Chile. His interests include lean manufacturing, technological change, green supply chain management and entrepreneurial orientation. His research has been published in journals such as International Journal of Operations and Production Management, International Journal of Production Economics, International Journal of Production Research, Supply Chain Management: An international Journal, Business Strategy and the Environment, and Decision Support Systems.

Mengying Feng is a professor of Supply Chain and Logistics Management at Chongqing Jiaotong University. Her research interests include low carbon shipping, green supply chain management, and port logistics. She has published some journal papers in International Journal of Production Economics, International Journal of Physical Distribution and Logistics Management, Service Industries Journal, Supply Chain Management: An International Journal, and Business Strategy and Environment. She has also got over 10 years of working experience in enterprises. 


\title{
Data-driven supply chain orientation and financial performance: The moderating effect of innovation focused complementary assets
}

\begin{abstract}
Drawing on the complementary assets framework, this study explores the moderating effect of innovation focused complementary assets (CA-I) on the relationship between a data-driven supply chain orientation (DDSCO) and firm financial performance. To test the moderating effect, survey data gathered from 329 manufacturing firms in China were analysed using a moderated regression analysis. The results indicate that DDSCO has a significant positive effect on financial performance and that capabilities for product and process innovation function as complementary assets moderating the DDSCO-performance relationship. The findings suggest that innovation focused complementary assets are performance differentiators when paired with a DDSO and explain why some firms obtain financial benefits from the development of a DDSCO while others do not. Specifically, competitive advantage from a DDSCO may not be realized unless CA-I and potentially other complementary assets, are harnessed thus providing useful practical guidance to managers. Hence the study provides empirical support for the complementary assets framework.
\end{abstract}

Keywords: Data-driven supply chains; Complementary assets; Innovation; Performance 


\section{Introduction}

Recent advances in information and communications technologies (ICT) have empowered firms to manage and analyse data to drive performance improvement and gain new market and business insights (Chong et al., 2016; Manyika et al., 2011; Sanders, 2014). For example, Amazon has successfully leveraged transaction data from buyers to both tailor offerings and set stocking levels at warehouses. The result has been increased revenue while curtailing growth in cost. Because of the scale, applications such as the Amazon example have been characterized as employing "big data". Big data refers to data that is in such volume, velocity, and variety that typical computing infrastructures cannot process it (Gandomi and Haider, 2015; McAfee and Brynjolfsson, 2012; Sanders, 2014); an orientation and ability to exploit such data in the supply chain context for improved performance is what we conceptualize as a data-driven supply chain orientation (DDSCO). Research suggests that supply chain managers effectively leveraging such data may derive useful insights into improving competitiveness (Davenport, 2006; Huang and Handfield, 2015) and as such managers are increasingly embracing data-driven supply chains as a critical source of value creation and competitive advantage (Chavez et al., 2017; Davenport, 2006; Tan et al., 2015). Recently, conceptual and case-based research has highlighted the importance of big data applications in operations and supply chain management (e.g., Dutta and Bose, 2015; Fosso Wamba et al., 2015; Schoenherr and Speier-Pero, 2015; Tan et al., 2015; Waller and Fawcett, 2013). However, since the research topic is in its infancy there is little published empirical evidence supporting the effect on business performance (Schoenherr and Speier-Pero, 2015; Waller and Fawcett, 2013; Yu et al., 2018). As such, there is a need for theoretical development (Chae et al., 2014).

This study employs Teece's (1986) complementary assets (CA) framework, which builds on the resource-based view of the firm (Wernerfelt, 1984) in its treatment of assets, and as such conceptualizes a DDSCO as an intangible firm resource (Waller and Fawcett, 2013); resources taking on characteristics of assets (Barney, 1991). CA suggests that leveraging effectively a resource such as DDSCO can lead to significant profit (Manyika et al., 2011; McAfee and Brynjolfsson, 2012) when in the context of another resource/asset. Big data applied to supply chains holds the promise of improving profit through reducing costs, enhancing revenue, and creating competitive advantage (Manyika et al., 2011; Sanders, 2014). While widespread use of increasingly granular customer and supplier data may improve the effectiveness of supply chain 
operations (Manyika et al., 2011; Sanders, 2014), merely possessing such resources does not guarantee a firm will achieve superior financial performance (Priem and Butler, 2001). More attention needs to be paid to the circumstances under which DDSCO strategies contribute to firm financial performance as there may be complementary variables that explain performance differentials (Christmann, 2000; Sousa and Voss, 2008). The present study investigates one such variable, innovation focused complementary assets.

This study employs Teece's (1986) concept of complementary assets in the empirical investigation of the contingency role of innovation focused complementary assets (CA-I) on the relationship between DDSCO and firm financial performance. Complementary assets include resources or capabilities that are required for capturing benefits associated with a primary asset (Christmann, 2000; Teece, 1986). According to Teece (1986), in dynamic and competitive environments firms need to possess complementary assets in order to gain an advantage from primary assets such as a DDSCO (Christmann, 2000). By investigating the moderating role of innovation assets this study provides insights that may enable managers to more fully understand how improved financial performance can be realized.

Drawing upon CA this study contributes to the literature by shedding light on the significance of CA-I in leveraging a DDSCO for performance improvement. In this study, we address two main research questions: 1) does developing a DDSCO drive superior financial performance? and 2) do innovation assets moderate the relationship between DDSCO and financial performance? The answers to these two questions will contribute to both theory and practice.

This study extends existing research by providing an empirical analysis that begins to reveal how DDSCO contributes to financial performance improvement. From a practical perspective, answering the first research question is important because guidance to managers for maximizing value from data to drive supply chain performance has been underdeveloped. From a methodological perspective, unlike recent research drawing of inferences based on a single case study (e.g., Dutta and Bose, 2015; Fosso Wamba et al., 2015; Tan et al., 2015), our study used survey data gathered from a cross section of 329 manufacturing firms in China. The second contribution of this study is the development and testing of theoretical arguments for the importance of CA-I as a moderator on the DDSCO-performance relationship. 
China provides an interesting setting for this study as it has become a global manufacturing centre that is rapidly evolving and playing an increasingly important role in global supply chains (Zhang, 2016; Zhao et al., 2011). The Ministry of Industry and Information Technology (MIIT, 2015 ) issued the "Made in China 2025" plan in 2015, with an emphasis on the application of smart manufacturing and big data analytics. A national big data strategy was first introduced in China's $13^{\text {th }}$ Five-Year Plan (2016-2020) in 2015, and listed as one of the important national strategies for promoting innovation-driven development (China Daily, 2017). With the state backing, many Chinese manufacturers (e.g., Lenovo, TCL and Haier) have adopted big data analytics to boost smart manufacturing and supply chain processes (China Daily, 2017). However, manufacturing firms face problems including the management and sharing of data, return on investment for big data analytics initiatives (China Daily, 2017; Yu et al., 2018). By addressing the two research questions in the context of the Chinese manufacturing industry, this study provides useful guidance to managers on how to develop data-driven supply chains for performance improvement.

\section{Theoretical background and hypotheses development}

\subsection{Theoretical background}

The present study uses Teece's (1986) concept of complementary assets, which stems from the resource-based view (Wernerfelt, 1984), to investigate the moderating effect of CA-I on the relationship between DDSCO and firm financial performance (see Figure 1).

Previous researchers have identified the importance of the contribution of new knowledge/technology resources and combinations of existing resources to securing competitive advantage (Helfat, 2000; Kogut and Zander, 1992). Resources are integrated to create capabilities, with each capability representing a unique combination of resources enabling such outcomes as improved market share (Lai et al., 2010a). Teece (1986) introduced the concept of complementary assets, which are resources or capabilities that facilitate capturing profits associated with a technology, innovation, or another asset (Helfat, 2000; Teece, 1986). Resources involved in forming complementary assets may be physical, human, or organizational (Barney, 1991). 


\subsection{Data-driven supply chain orientation}

The conceptualizations of big data have evolved rapidly and various authors focus on different dimensions (Fosso Wamba et al., 2015; Gandomi and Haider, 2015). Herein we follow the work of Fosso Wamba et al. (2015, p. 235), and define a big data capability as "a holistic approach to manage, process, and analyse 5V's in order to create actionable insights for sustained value delivery, performance measurement, and establishing competitive advantage”. Researchers and practitioners have used the notion of " $5 \mathrm{~V}$ 's" to describe big data: volume (large amounts of data), variety (multiple sources and formats of data), velocity (speed and frequency of data generation/delivery), veracity (quality of data and the level of trust in various data sources), and value (economic value generated from data) (Fosso Wamba et al., 2015; Gandomi and Haider, 2015; McAfee and Brynjolfsson, 2012; Russom, 2011). In the present study, we define data-driven supply chain orientation (DDSCO) as the presence of an infrastructure to process and analyse big data and the strategic intent to leverage the resulting insights to improve supply chain performance (Chavez et al., 2017; Yu et al., 2018).

Big data has become available to almost every sector and function of the global economy (Manyika et al., 2011) and is growing in importance as a driver of better decision making and improved business performance for those firms able to leverage it (Stank et al., 1999). Today's supply chain professionals are inundated with data that has the potential to enable new ways of organizing and analysing supply chain processes and hence potentially improve supply chain performance. For example, performance improvement could be realized through access to dash boards that are updated in real time. Such dash boards could include not just inventory positions and production output, but also dynamic demand forecasts. Hence alerts could be provided to managers that call attention to supply-demand imbalances. Such decision support tools would facilitate improved managerial decision making (Jacobs, 2013) with a logical outcome being improved firm financial performance.

Cross functional databases such as those found in product lifecycle management (PLM) software suites can facilitate concurrent engineering and the rapid design of prototypes. These prototypes can be brought to focus groups linked to market segments identified by the data. The feedback can be quickly embodied in the new product and then released to the market. Such speedy release to the market may provide a first mover advantage resulting in a larger market share. Conversely for firms more risk adverse, access to big data and the capacity to act upon it 
may facilitate a fast follower strategy. The firm could offer a widget better than the competition's quickly upon discerning from the data that the nascent market will be important.

The ability and willingness to use big data could reveal opportunities to cross sell or even opportunities to create a product / service to complement one already offered. The ability to aggregate and analyse customer data may lead to insights into which features should be added to a product to maximize its appeal to the market. Firms with exceptional data management capabilities may actually be able to build data related capabilities into their products that allow the product to be perfectly tailored to the customers need and in doing so enhance its value, which may lead to the ability to extract a price premium.

Firms with a big data capable infrastructure have the potential to revolutionize supply chain performance (Chavez et al., 2017; Waller and Fawcett, 2013). This is evidenced by recent nascent successes with successful exploitation of big data that have caused leading industry practitioners to claim that leveraging big data is the next "blue ocean" in nurturing business performance (Kwon et al., 2014). In fact, some firms are already attempting to harness big data to gain new insights and identify business opportunities or to understand elements of product and process design, suppliers and customers, and market demand (Sanders, 2014; Schoenherr and Speier-Pero, 2015; Tan et al., 2015). For example, Hopkins and Brokaw (2011) described how leveraging big data could enhance call centre responsiveness. Deploying a big data strategy to the supply chain could potentially lead to improvements in efficiency and effectiveness through activities such as monitoring the location, transfer and acceptance of products and services, advanced demand forecasting and supply planning, and understanding behaviour of customers and suppliers (Davenport, 2006; Davenport et al., 2012; Kwon et al., 2014; Waller and Fawcett, 2013).

Recently, a few studies using case study methodology (e.g., Dutta and Bose, 2015; Fosso Wamba et al., 2015; Tan et al., 2015) have highlighted the importance of using big data strategies in operations and supply chain management. For example, Tan et al. (2015) indicate that a data analytic orientation enables firms to leverage big data to gain competitive advantage by enhancing their supply chain capabilities. Drawing upon the findings from a systematic review and a longitudinal case study, Fosso Wamba et al. (2015) presented an interpretive framework analysing definitional perspectives and applications of big data. The main findings suggest that creating organizational value from big data can further real-time access and 
information sharing across local and national government agencies, which in turn leads to enhanced emergency service response through more effective decision-making. However, all of these studies involved deriving conclusions purely based on a single case study, which could be fraught with bias (Dutta and Bose, 2015). Furthermore, these studies assume gains will accrue to financial performance, and as such examining the DDSCO-financial performance link using cross sectional data is a logical next step in the development of the topic in the literature. The present study seeks to fill that gap in part. Consistent with published case research, we posit that firms employing a DDSCO will manifest enhanced financial performance and as such propose the following hypothesis.

H1: DDSCO is positively associated with financial performance.

\subsection{Moderating effect of innovation focused complementary assets}

Teece (1986) defined complementary assets as resources or capabilities that allow firms to capture the profits associated with a strategy, technology, or innovation which could include capabilities in manufacturing, logistics and distribution channels, after-sales service, and related technologies. Previous studies have suggested that complementary assets include product and process innovation (Christmann, 2000) and may include assets relating to IT (Feng et al., 2012), design-manufacturing integration (Swink and Nair, 2007), R\&D, and production (Rothaermel and Hill, 2005). In this way, we follow the work of Christmann (2000) and define innovation focused complementary assets $(C A-I)$ as those associated with product and process innovation. In a supply chain context CA-I are resources and/or capabilities which include trying new methods and technologies, investing in new equipment and machinery, and introducing product and process innovations in the supply chain context (Christmann, 2000; Lai et al., 2010b; Yu, 2015). If Teece's (1986) theorization is correct, then firms will manifest performance differentials to the extent they leverage complementary assets. In this study, that theory will be tested and found true to the extent that a moderating relationship between CA-I and DDSCO is confirmed.

Previous research (e.g., Christmann, 2000; Lai et al., 2010b) has suggested that if successful implementation of supply chain management practices requires complementary assets, only firms that possess such assets will be able to gain and sustain a competitive advantage; the advantage being reflected in better financial performance. In other words, it could be argued that 
CA-I may act as a moderator of the relationship between DDSCO and financial performance. Consistent with Christmann (2000) this study uses measures of product and process innovation, use of the latest technology, and the acquisition of new equipment to represent CA-I.

Firm culture is a candidate to consider when pursuing the question of why the moderating relationship may exist (Kull and Wacker, 2010). There is a distinct culture associated with innovation and one aspect of it is market experimentation (Yoo and Kim, 2015). The willingness to try new products in the market goes hand in hand with DDSCO. Where DDSCO requires that firms use the data based resources to enhance the value of products and leverage selling opportunities across the product portfolio, the culture associated with CA-I provides the impetus for it (Closs et al., 2008). Further, synergies may be gained from an organization that is aligned (Jacobs and Swink, 2011). If engineering and marketing are pushing new products to the market, then having a manufacturing function that is willing to adopt new tooling and production techniques will support the rapid transition from ideation to market.

Another aspect of culture associated with innovation entails the inquisitiveness and exploration manifested in the product development process (Waguih, 2017). Inquisitiveness drives science and technology forward. The DDSCO organization through its ability to synthesize information has the ability to inform the decisions and subsequent directions engineers take as they develop a new product, technology, or service. The resulting complementarity should lead to better products released more quickly to the market with a corresponding increase in revenue and profit.

Reaching out beyond the company boundaries is common in corporate innovation settings (Waguih, 2017). It is often a requirement because seldom does all the knowledge on a topic reside within the company. Hence to solve technical problems engineers reach out to suppliers and other resources to secure the information needed to solve the problem at hand. The notion of collaborating beyond the company bounds is exactly the trait needed to collaborate on matters of trade within the supply chain (Koufteros et al., 2005; Petersen et al., 2005). As such, the longstanding perspective of innovation related workers of suppliers as collaborators rather than as competitors or an expense to be reduced is an essential perspective for the DDSCO organization. Working together with suppliers will likely yield a better market outcome (Petersen et al., 2005) 
The focus on the customer is another aspect where CA-I and DDSCO can complement one another. A DDSCO organization can provide specific information to engineers about attributes important to the market. In fact, the customer orientation resident in DDSCO and the data associated with it can be infused into the stage gate decision process supporting product development. Conversely a development organization's focus on creating technologies than can be successfully commercialized may cause the development organization to leverage the data processing and analysing capabilities resident within a DDSCO firm to better target the market. Indeed, when firms focus on the customer in this way, financial performance has been shown to improve (Droge et al., 2012).

An advantage that could be achieved from the infrastructure associated with a DDSCO is the ability to identify the strategic usefulness of a new technology or manufacturing technique. Toward that end, the willingness to make new capital investments and embrace new technologies could be exploited for gain in the market place. Essentially the firm can roll out features not available in competing products or provide products at a price point that competitors cannot match. Both scenarios may enhance revenue and market share

While previous studies (e.g., Christmann, 2000; Feng et al., 2012; Lai et al., 2010a, b; Swink and Nair, 2007) have not considered the CA-I to DDSCO relationship, they have provided empirical support for the moderating role of generic complementary assets in different business contexts and as such are supportive of the prior logical arguments. For instance, Christmann (2000) examined the role of complementary assets in gaining a cost advantage from environmental management practices, and found that capabilities for process innovation moderate the relationship between best practices of environmental management and cost advantage. Additionally, Lai et al. (2010b) found that complementary assets moderate the negative relationship between technological diversification and organizational divisionalization and Feng et al. (2012) found that IT implementation plays a role of complementary asset to customer involvement and communication with customers.

We therefore suggest that CA-I plays an important moderating role in the DDSCOfinancial performance relationship. Specifically, product and process innovation are required when firms become oriented toward the leveraging of big data for performance improvement (Christmann, 2000; Colombo et al., 2006; Lai et al., 2010a, b; Rothaermel and Hill, 2005; Teece, 1986). The new technologies are of little value in the absence of complementary assets, 
especially in the absence of the specialized or co-specialized complementary assets, such as high levels of capability for process innovation and implementation (Christmann, 2000; Lai et al., 2010b; Teece, 1986). Even if other firms can imitate the data-driven supply chain practices, they will not be able to achieve competitive advantage from imitation if they do not have access to the necessary complementary assets (Christmann, 2000). Thus, drawing upon the CA theory we argue that firms possessing a high level of capability for product and process innovation are able to achieve superior financial performance when CA-I is coupled with the development of a DDSCO. Given the forgoing we propose the following hypothesis.

H2: Innovation focused complementary assets moderate the relationship between a datadriven supply chain orientation and financial performance.

\section{Research method and data}

\subsection{Sample and data collection}

Survey data for this study was gathered from manufacturing firms in China during June 2014 to January 2015. The Chinese manufacturing industry provides an interesting setting for this study. As noted above, China's 13 ${ }^{\text {th }}$ Five-Year Plan (2016-2020) and the "Made in China 2025" plan issued in 2015 presented new opportunities for manufacturing firms to expand the use of big data in their operations and supply chain processes. Many Chinese manufacturers (e.g., Lenovo, TCL and Haier) have developed big data strategies to boost smart manufacturing and improve business performance (China Daily, 2017).

With regard to the sample pool, we chose five regions that represent different stages of economic development in China including Bohai Sea Economic Area, Central China, Pearl River Delta, Southwest China, and Yangtze River Delta (Zhao et al., 2006). To obtain a representative sample we randomly selected 1500 manufacturing firms from China Enterprises Directory across the five regions. We contacted the key informants by telephone and email before sending out the questionnaires to obtain their preliminary agreement to take part in the study. We then sent the questionnaires with a cover letter explaining the main purpose of the study and assuring confidentiality to 1230 firms that agreed to participate and provide information for this research. Most of the informants held a position such as CEO, president, director, or general manager, and had been in their current position for more than five years. Thus, based on position and tenure it is reasonable to expect that the informants could offer deep insights into the functional activities 
and be knowledgeable about the content of the inquiry (Jacobs et al., 2007). After several reminders, a total of 337 questionnaires were returned. Eight returned questionnaires were discarded because of significant missing data, which resulted in 329 completed and useable questionnaires representing an effective response rate of $26.8 \%$. Table 1 provides a summary of demographic characteristics of respondents. As shown in Table 1 data were obtained from respondents in a wide variety of manufacturing firms.

Insert Table 1

\subsection{Measures and questionnaire design}

We developed first the English version of the questionnaire and then translated it into Chinese, then conducted a back-translation to ensure conceptual equivalence. We also checked the back-translated English version against the original English version to ensure the reliability of the questionnaire (Flynn et al., 2010; Zhao et al., 2011). Some questions were reworded to improve the accuracy of the translation and relevance to business practices in China. Even though the measurement scales were used prior and demonstrated to be valid we took extra steps before administering the survey. Due to the unique characteristics of the Chinese manufacturing industry (Zhao et al., 2006) we modified in minor ways the existing measurement scales in order to account for language and cultural differences. To assess the content validity of the scales we consulted three academic experts who were selected on the basis of their research and consulting activities. Furthermore, we conducted a pilot test with five randomly selected manufacturers using semi-structured interviews. Based on the feedback redundant and ambiguous items were eliminated or modified.

The resulting measurement items used in this study are reported in Table 2. Since there was no existing measurement instrument for DDSCO, we developed new items based on feedback from senior executives, our observations during company visits, and the guidance from knowledgeable academic experts (e.g., Manyika et al., 2011; Sanders, 2014). In addition, the newly developed items were reviewed and assessed by five senior managers during the survey pretesting to ensure the reliability and validity of measurement instruments. Additionally, a series of analyses were conducted in order to further assess the reliability and validity of the scales. The results presented in Sections 3.4. and 3.5 confirm the reliability and validity of the DDSCO construct. In this study, we measured DDSCO using five items: establish a flexible and 
open central data environment, build consistent interoperable and cross-functional department databases, aggregate customer data and make them widely available to improve service level, implement advanced demand forecasting and supply planning across suppliers, and implement lean manufacturing and model production virtually. Respondents were asked to respond using a seven-point scale, namely from 1 "strongly disagree" to 7 "strongly agree".

The measures for $C A-I$ were adapted from Christmann (2000) and focus on the capabilities related to product and process innovation. A total of four items were used to measure CA-I: being the first in the industry to try new methods and technologies, investing in new equipment and machinery, being leaders in introduction of product innovations, and being leaders in introduction of process innovations. All these items were measured on a 1-7 scale $(1=$ strongly disagree and $7=$ strongly agree).

Financial performance was measured using four perceptual measures including growth in sales, growth in return on investment, return on assets (ROA), and growth in ROA (Flynn et al., 2010; Narasimhan and Kim, 2002; Yu et al., 2013). In accordance with the previous studies respondents were asked to assess their firm's performance relative to the performance of main competitors over the last three years. The indicators were measured using a seven-point Likert scale (ranging from 1 "much worse than your major competitors" to 7 "much better than your major competitors").

Insert Table 2

We included five control variables in our conceptual model: firm age, firm size, industry type, firm ownership and geographical region (see Table 1). First, firm size was measured as the number of employees. Larger firms may have more resources for managing supply chain activities in a data-rich environment, and thus may achieve higher business performance than small firms (Yu et al., 2013). Second, firm age was measured by the number of years since firm foundation. Firm age might be related to business performance (Terjesen et al., 2011) because older firms may be more likely to overcome performance-threatening liabilities (Stinchcombe, 1965). Third, firm ownership as a form of control and governance may influence the implementation of supply chain activities and thus business performance (Zhao et al., 2011). In this study, the dummy variable Ownership1 refers to state-owned manufacturer, Ownership2 refers to private Chinese manufacturer, and Ownership3 refers to wholly foreign-owned manufacturer. The base group is joint venture manufacturer. Fourth, the type of industry was 
controlled because firms in the different manufacturing industries may develop different levels of DDSCO for performance improvement (Yu, 2015). The dummy variable Industry1 refers to automobile, Industry 2 refers to chemicals and petrochemicals, Industry 3 refers to electronics and electrical, and Industry4 refers to textiles and apparel. As shown in Table 1 they are the four largest manufacturing industries in this study. The base group is other industries. Fifth, China is not a homogenous country and companies in different geographical regions that are at different stages of economic development may have different levels of DDSCO and performance (Zhao et al., 2006, 2011). The dummy variable Region1 refers to Southwest China, Region2 refers to Central China, Region3 refers to Bohai Sea Economic Area, and Region4 refers to Yangtze River Delta. The base group is Pearl River Delta.

\subsection{Non-response bias and common-method bias}

To assess non-response bias, we followed the method suggested by Lessler and Kalsbeek (1992) comparing early and late responses on the demographic characteristics of number of employees, annual sales, and industry type. The t-test results reveal that there was no significant statistical difference $(p<0.05)$ among the category means for the demographic characteristics. Thus, non-response bias is not likely to be a concern in this study.

We adopted several approaches to assess potential common method bias (Podsakoff et al., 2003; Podsakoff and Organ, 1986). First, when designing the questionnaire, we used different instructions for different scales and the adjacent variables in the conceptual framework were put in distinct sections (Zhao at al., 2011). Furthermore, when contacting the key informant in each randomly selected firm we suggested that the relevant senior functional or departmental managers should be consulted when answering the sections of the questionnaire aligned with that manager's responsibilities (Li et al., 2008). Second, we performed confirmatory factor analysis (CFA) based Harman's single-factor test (Flynn et al., 2010; Podsakoff et al., 2003; Zhao at al., 2011). The model fit indices of $\chi^{2} / \mathrm{df}=25.12$, RMSEA $=0.27, \mathrm{CFI}=0.57, \mathrm{IFI}=0.57, \mathrm{TLI}=$ 0.49 , and SRMR $=0.20$ were unacceptable and significantly worse than those of the measurement CFA model. This result indicates that a single factor model is not acceptable and that common method bias is unlikely. Third, we used a latent factor to capture the common variance among all observed variables in the measurement model (Podsakoff et al., 2003; Williams and Anderson, 1994; Zhao et al., 2011). The resulting model fit indices were not 
significantly different from those of the measurement model and the item loadings for their factors were still significant in spite of the inclusion of a common latent factor. In summary, we conclude that common method bias is not a serious concern in this study.

\subsection{Unidimensionality and reliability}

We performed a series of analyses to assess the unidimensionality and reliability of the theoretical constructs. The results are reported in Tables 2 and 3.

We conducted a CFA to assess the unidimensionality of the theoretical constructs (Gerbing and Anderson, 1988). The CFA results shown in Table $2\left(\chi^{2} / \mathrm{df}=2.966, \mathrm{RMSEA}=0.077 ; \mathrm{CFI}=\right.$ 0.967; IFI = 0.967; TLI = 0.958; SRMR =0.046) reveal a good model fit (Hair et al., 2010; Hu and Bentler, 1999). Thus, unidimensionality is ensured.

Cronbach's alpha and composite reliability (CR) were used to examine construct reliability. Table 2 shows that the Cronbach alpha and CR of all the constructs were well above the recommended lower limit of 0.70 (Hair et al., 2010; Nunnally, 1978; O’Leary-Kelly and Vokurka, 1998). Thus, the theoretical constructs are reliable.

\subsection{Validity}

In this study, we evaluated content, discriminant and convergent validity of each measurement scale (Bollen, 1989; O’Leary-Kelly and Vokurka, 1998).

Content validity was established through our comprehensive analysis of the relevant literature, iterative construct review, and the pilot test with academic and industrial experts (Flynn et al., 2010; Zhao et al., 2011).

With regard to convergent validity, as shown in Table 2, all indicators in their respective constructs had statistically significant $(p<0.001)$ factor loadings greater than 0.50 , which suggests convergent validity of the theoretical constructs (Hair et al., 2010). Furthermore, the CFA results reported in Table 2 also reveal that the standardized coefficients for all items greatly exceeded twice their standard errors and that the $\mathrm{t}$-values were all larger than 2 which further demonstrates convergent validity (Hair et al., 2010). Additionally, the average variance extracted (AVE) of each construct greatly exceeded the recommended critical value of 0.50 (Fornell and Larcker, 1981), which indicates strong convergent validity. In summary, we conclude that our theoretical constructs express sufficient convergent validity. 
Discriminant validity was examined by comparing the correlation between the construct and the square root of AVE. Discriminant validity is indicated if the AVE for each multi item construct is greater than the shared variance between constructs (Fornell and Larcker, 1981). The results reported in Table 3 indicate that the square root of AVE of all the constructs was greater than the correlation between any pair of them. Thus, discriminant validity is ensured (Fornell and Larcker, 1981).

Insert Table 3

\section{Data analysis and results}

Ordinary least square (OLS) regression was used in this study to test the relationship between DDSCO and financial performance and the moderation effect of CA-I on the DDSCO financial performance relationship (Hair et al., 2010). In the OLS regression a dependent variable was regressed on an independent variable, a control variable (if any), a moderator variable, and a product term between the independent and the moderator variables (Hair et al., 2010). The impact of the moderator variable was assessed using a three-stage regression: (1) control variables, (2) main effect variables, and (3) moderator variables (Hair et al., 2010).

Table 4 provides the results of the OLS regression. In all models financial performance is the dependent variable and the variance inflation factor (VIF) values are lower than 5.0 suggesting that multicollinearity is not an issue (Mason and Perreault, 1991). As shown in Table 4 , DDSCO is significantly and positively associated with financial performance $(\beta=0.405, p<$ 0.001) which lends support to H1. Table 6 also shows that the coefficient of cross-product term (DDSCO $\times$ CA-I) is significant $(\beta=0.097, p<0.05)$ which indicates that CA-I moderates the relationship between DDSCO and financial performance. Thus, $\mathrm{H} 2$ is supported. To gain further insights into the moderating effect, following Aiken and West (1991) we plotted the relationship between DDSCO and performance (see Figure 2) to demonstrate how CA-I moderates the relationship. Figure 2 shows that the effect of DDSCO on financial performance is more pronounced when CA-I is high. Thus, showing that the greater the level of CA-I the stronger the positive impact of DDSCO on financial performance.

- Insert Table 4 Insert Figure 2 


\section{Discussion and implications}

This study employed the complementary assets framework (Teece, 1986) to empirically investigate the moderating effect of CA-I on the DDSCO - performance relationship. We found that DDSCO is positively and significantly associated with financial performance and that CA-I positively moderates the relationship between DDSCO and financial performance. Our findings suggest that innovation focused complementary assets are a significant part of successfully leveraging a DDSCO and may explain why some firms obtain financial benefits from the development of DDSCO while others do not.

\subsection{Theoretical implications}

There has been much discussion among academics and practitioners about big data applications in supply chain operations and the benefits and challenges of developing a datadriven supply chain (Dutta and Bose, 2015; Fosso Wamba et al., 2015; Manyika et al., 2011; Tan et al., 2015). The important question is whether using big data in supply chain processes is just hype or if it has a real effect in enabling performance improvement (Chae et al., 2014). One finding of this study is that DDSCO significantly influences financial performance and as such suggests performance impacts from big data are real, and that a DDSCO is a resource in the resource-based view sense. A data-driven supply chain orientation may be a "resource" because it transforms the decision-making process by facilitating enhanced visibility of supply chain operations, which can be synthesized to achieve superior financial performance. DDSCO leads to new frontiers in supply chain transparency, visibility, and process automation which enables multiple supply chain partners to seamlessly interact in the joint design, production, delivery, and service of complex customer orders. Our findings suggest that developing such data-driven supply chains should drive greater financial performance.

Another important finding confirmed by this study is the moderating role of CA-I. More specifically, we found that the capabilities for product and process innovation are important complementary assets moderating the relationship between DDSCO and financial performance. This is an important finding since there has been no previous empirical investigation of this effect in a data-driven supply chain orientation context. Thus, the application of the CA framework to the analysis of DDSCO highlights the importance of heterogeneity in firm resources and capabilities; a variable that has so far been ignored in the examination of the 
financial benefits of developing data-driven chains (Christmann, 2000; Teece, 1986). The results provide strong evidence of a moderating effect, which supports the perspective that innovation focused complementary assets are an important resource for firms in order to achieve the maximum potential financial benefits from developing DDSCO. As shown in Figure 2, the higher a firm's CA-I the greater the financial performance it derived from a DDSCO. Thus, our study extends the prior literature (e.g., Christmann, 2000; Feng et al., 2012; Lai et al., 2010a, b; Swink and Nair, 2007) by providing empirical evidence supporting the moderating role of innovation focused complementary assets in the supply chain context.

\subsection{Managerial implications}

Our results hold important implications for managerial practice. First, the results of this study reveal that the effect of DDSCO on financial performance is positive and significant; thus demonstrating that leveraging big data across the supply chain has a real effect in enabling performance improvement. As such this study suggests that managers employing strategies to incorporate big data in supply chain contexts can expect to realize returns for their investments. In an increasingly complex data-driven environment, analysing and interpreting big data in supply chain operations has become an imperative for today's supply chain executives. These executives should understand that a DDSCO can be instrumental in managing supply chain complexity and driving performance.

However, supply chain executives should not lose sight of the role of complementary assets. Our finding of the moderating effect of CA-I suggests that in conjunction with developing a DDSCO firms should examine their existing innovation resources and capabilities. Improvements in these resources and capabilities will serve to amplify the benefits found from a DDSCO. The importance of CA-I suggests that managers maintain an awareness that the starting point for developing DDSCO has to be the resources and capabilities that firms can leverage or readily acquire. In fact, we suggest that firms lacking in CA-I may be better off developing DDSCO later than other firms so that they can learn from early implementers. The lack of complementary resources such as CA-I provides insight into why some firms are not able to gain competitive advantage from developing DDSCO.

Third, capabilities for product and process innovation were found to be complementary assets that moderated the DDSCO - performance relationship. Managers can use the finding as a 
starting point for determining the particular mix of assets required to achieve superior firm performance in their unique context. However, they should recognize that even if they imitate the DDSCO of other firms they may not be able to achieve competitive advantage if they do not properly harness CA-I and potentially other complimentary resources. Managers can use the validated measures of CA-I provided in this study as a benchmark for assessing their own company's level of product and process innovation.

Lastly, because the fundamental nature of business competition has shifted from that of competition between individual firms to competition between entire supply chains, managers need to identify, utilize, and analyse data as effectively as possible in order to drive improved financial performance. Developing such capabilities should be a managerial priority as it will lead better financial performance.

\subsection{Limitations and future research directions}

Several limitations in our study provide potential directions for further research. First, this study established the importance of innovation focused complementary assets (i.e., capabilities for product and process innovation) in moderating the relationship between DDSCO and financial performance. However, developing a supply chain that can leverage big data in tomorrow's dynamic and competitive environments may require different complementary assets, e.g. the use of data science and predictive analytics (Waller and Fawcett, 2013), IT (Feng et al., 2012), design-manufacturing integration (Swink and Nair, 2007), R\&D, production, and sales force assets (Rothaermel and Hill, 2005). Future research should identify and empirically investigate which particular complementary assets associated with a DDSCO are also required to enhance business performance and in which industries they are most effective. Second, future work could evaluate the importance of factors such as competitive environment, environmental uncertainty, and information exchange because these may influence the application of big data in logistics and supply chain management. Further, future research could investigate the relative importance of differing types of complementary assets within these various contexts and extend the conceptual model proposed in the present study by investigating how these factors influence DDSCO and performance. Further still, there may be intermediate outcomes between DDSCO and performance and we encourage future studies investigating the nature and identity of such outcomes. Third, our sample is from companies within the Chinese economy. For cross-country 
validation purposes future research may test our proposed model in different countries or explore the evolution of capabilities over time.

\section{Conclusions}

Drawing on Teece's (1986) framework of complementary assets this study investigated the moderating effect of CA-I on the relationship between DDSCO and financial performance using survey data gathered from 329 manufacturing firms in China, and made significant contributions to both theory and practice. The major contributions are as follows.

First, we found that firms with higher levels of DDSCO are more likely to have better financial performance. Our study thus extends the prior literature by providing empirical evidence to support the significant relationship between DDSCO and financial performance. This finding is important since there has been much debate recently among academics and practitioners about whether DDSCO can drive performance improvement; possibly because DDSCO research is still in its infancy (Chae et al., 2014; Schoenherr and Speier-Pero, 2015; Waller and Fawcett, 2013) and most recent research has involved drawing conclusions from a single case.

Second, the study extends existing research on the effect of DDSCO on performance by examining the moderating effect of CA-I. Although complementary assets have been found valuable in previous studies (e.g., Feng et al., 2012; Lai et al., 2010a, b; Lin and Wang, 2015; Swink and Nair, 2007) the role that innovation focused complementary assets play in the DDSCO - performance relationship has not yet been investigated.

Third, this study contributes to managerial practice. Our study established the importance of capabilities for product and process innovation as complementary asses in moderating the DDSCO - performance relationship. Executives can use the findings as guidance for selecting assets particular to their environment to achieve superior firm performance through a DDSCO. 


\section{Appendix: questionnaire}

1. Data-driven supply chains. Please indicate the degree to which you agree to the following statements relating to your company's big data analytics $(1=$ strongly disagree; $7=$ strongly agree)

- Our company establishes a flexible and open central data environment.

- Our company builds consistent interoperable, cross-functional department databases to enable concurrent engineering, rapid experimentation and simulation, and co-creation.

- Our company aggregates customer data and make them widely available to improve service level, capture cross- and up-selling opportunities, and enable design-to-value.

- Our company implements advanced demand forecasting and supply planning across suppliers.

- Our company implements lean manufacturing and model production virtually (such as digital factory) to create process transparency, develop dashboards, and visualize bottlenecks.

2. Financial performance. Please provide an estimate of and evaluate in the scale below how your firm compares to your major industrial competitors over the last three years $(1=$ much worse than your major competitors; $7=$ much better than your major competitors)

- Growth in sales.

- Growth in return on investment.

- Return on assets (ROA).

- Growth in ROA.

3. Complementary assets. Please indicate the degree to which you disagree or agree with the following statements by comparing your firm to your major industrial competitors $(1=$ strongly disagree; 7 = strongly agree)

- We focus on being the first in the industry to try new methods and technologies.

- We focus on investing in new equipment and machinery.

- We have been leaders in introduction of product innovations over the last 3 years.

- We have been leaders in introduction of process innovations over the last 3 years. 


\section{References}

Aiken, L.S., West, S.G., 1991. Multiple Regression: Testing and Interpreting Interactions. California: Sage Publications, Inc Newbury Park.

Barney, J.B., 1991. Firm resources and sustained competitive advantage. Journal of Management 17 (1), 99-121.

Bollen, K.A., 1989. Structural Equations with Latent Variables. John Wiley \& Sons, New York.

Chae, B., Olson, D., Sheu, C., 2014. The impact of supply chain analytics on operational performance: A resource-based view. International Journal of Production Research 52 (16), 4695-4710.

Chavez, R., Yu, W., Jacobs, M.A., Feng, M., 2017. Data-driven supply chains, manufacturing capability and customer satisfaction. Production Planning \& Control 28 (11-12), 906-918.

China Daily, 2017. National big data strategy. Available at: http://usa.chinadaily.com.cn/a/201712/13/WS5a3070b2a3108bc8c672b172.html (accessed 8th June 2018).

Chong, A.Y.L., Li, B., Ngai, E.W.T., Ch'ng, E., Lee, F., 2016. Predicting online product sales via online reviews, sentiments, and promotion strategies. International Journal of Operations \& Production Management 36 (4), 358-383.

Christmann, P., 2000. Effects of "best practices" of environmental management on cost advantage: The role of complementary assets. Academy of Management Journal 43, 663-680.

Closs, D., Jacobs, M., Swink, M., Webb, G.S., 2008. Toward a theory of competencies for the management of product complexity: Six case studies. Journal of Operations Management 26 (5), 590-610.

Colombo, M.G., Grilli, L., Piva, E., 2006. In search of complementary assets: The determinants of alliance formation of high-tech start-ups. Research Policy 35, 1166-1199.

Davenport, T.H., 2006. Competing on analytics. Harvard Business Review 84 (1), 99-107.

Davenport, T.H., Barth, P., Bean, R., 2012. How “big data” is different. MIT Sloan Management Review 54 (1), 43-46.

Droge, C., Jacobs, M., Vickery, S., 2012. An empirical study: Does supply chain integration mediate the relationship between product/process strategy and service performance? International Journal of Production Economics 137 (2), 250-262. 
Dutta, D., Bose, I., 2015. Managing a Big Data project: The case of Ramco Cements Limited. International Journal of Production Economics 165, 293-306.

Feng, T., Sun, L., Zhu, C., Sohal, A.S., 2012. Customer orientation for decreasing time-tomarket of new products: IT implementation as a complementary asset. Industrial Marketing Management 41, 929-939.

Flynn, B.B., Huo, B., Zhao, X., 2010. The impact of supply chain integration on performance: A contingency and configuration approach. Journal of Operations Management 28, 58-71.

Fornell, C., Larcker, D.F., 1981. Evaluating structural equation models with unobservable variables and measurement error. Journal of Marketing Research 18 (1), 29-50.

Fosso Wamba, S, Akter, S., Edwards, A., Chopin, G., Gnanzou, D., 2015. How “big data” can make big impact: Findings from a systematic review and a longitudinal case study. International Journal of Production Economics 165, 234-246.

Gandomi, A., Haider, M., 2015. Beyond the hype: Big data concepts, methods, and analytics. International Journal of Information Management 35, 137-144.

Gerbing, D.W., Anderson, J.C., 1988. An updated paradigm for scale development incorporating unidimensionality and its assessment. Journal of Marketing Research 25, 186-192.

Hair, J.F.Jr., Black, W.C., Babin, B.J., Anderson, R.E., Tatham, R.L., 2010. Multivariate Data Analysis. 7th ed., Upper Saddle River, NJ: Pearson Education.

Helfat, C.E., 2000. Guest editor's introduction to the special issue: the evolution of firm capabilities. Strategic Management Journal 21, 955-959.

Hopkins, M., Brokaw, L., 2011. Matchmaking with math: How analytics beats intuition to win customers. Sloan Management Review 52 (2), 35-41.

Hu, L., Bentler, P.M., 1999. Cut-off criteria for fit indexes in covariance structure analysis: Conventional criteria versus new alternatives. Structural Equation Modelling: A Multidisciplinary Journal 6 (1), 1-55.

Huang, Y.Y., Handfield, R.B., 2015. Measuring the benefits of ERP on supply management maturity model: A "big data" method. International Journal of Operations \& Production Management 35 (1), 2-25.

Jacobs, M., 2013. Complexity: Toward an empirical measure. Technovation 33 (4), 111-118. 
Jacobs, M., Swink, M., 2011. Product portfolio architectural complexity and operational performance: Incorporating the roles of learning and fixed assets. Journal of Operations Management 29 (8), 677-691.

Jacobs, M.A., Vickery, S., Droge, C., 2007. The effects of product modularity on competitive performance: Do integration strategies mediate the relationship? International Journal of Operations and Production Management 27, 1046-1068.

Kogut, B., Zander, U., 1992. Knowledge of the firm, combinative capabilities, and the replication of technology. Organization Science 3 (3), 383-397.

Koufteros, X., Vonderembse, M., Jayaram, J., 2005. Internal and external integration for product development: The contingency effects of uncertainty, equivocality, and platform strategy. Decision Sciences 36 (1), 97-133.

Kull, T., Wacker, J., 2010. Quality management effectiveness in Asia: The influence of culture. Journal of Operations Management 28, 223-239.

Kwon, O., Lee, N., Shin, B., 2014. Data quality management, data usage experience and acquisition intention of big data analytics. International Journal of Information Management 34 (3), 387-394.

Lai, H.C., Chiu, Y.C., Liaw, Y.C., 2010b. Can external corporate venturing broaden firm's technological scope? The role of complementary assets. Journal of Engineering and Technology Management 27, 183-196.

Lai, H.C., Chiu, Y.C., Liaw, Y.C., Lee, T.Y., 2010a. Technological diversification and organizational divisionalization: The moderating role of complementary assets. British Journal of Management 21 (4), 983-995.

Lessler, J., Kalsbeek, W., 1992. Nonsampling Error in Surveys. John Wiley \& Sons, New York. Li, Y., Liu, Y., Li, M., Wu, H., 2008. Transformational offshore outsourcing: Empirical evidence from alliances in China. Journal of Operational Management 26 (2), 257-274.

Lin, J.H., Wang, M.Y., 2015. Complementary assets, appropriability, and patent commercialization: Market sensing capability as a moderator. Asia Pacific Management Review 20, 141-147.

Manyika, J., Chui, M., Brown, B., Bughin, J., Dobbs, R., Roxburgh, C., Byers, A.H., 2011. Big Data: The Next Frontier for Innovation, Competition, and Productivity. McKinsey Global Institute, San Francisco. 
Mason, C., Perreault, W., 1991. Colinearity, power, and interpretation of multiple regression analysis. Journal of Marketing Research 28 (3), 268-280.

McAfee, A., Brynjolfsson, E., 2012. Big data: The management revolution. Harvard Business Review 90 (10), 60-68.

Ministry of Industry and Information Technology (MIIT), 2015. Made in China 2025. Available at: http://www.miit.gov.cn/ (accessed 8th June 2018).

Narasimhan, R., Kim, S.W., 2002. Effect of supply chain integration on the relationship between diversification and performance: Evidence from Japanese and Korean firms. Journal of Operations Management 20 (3), 303-323.

Nunnally, J.C., 1978. Psychometric Theory. McGraw-Hill, New York.

O'Leary-Kelly, S.W.O., Vokurka, R.J., 1998. The empirical assessment of construct validity. Journal of Operations Management 16 (4), 387-405.

Petersen, K.J., Handfield, R.B., Ragatz, G.L., 2005. Supplier integration into new product development: Coordinating product, process and supply chain design. Journal of Operations Management 23 (3), 371-388.

Podsakoff, P.M., MacKenzie, S., Lee, J., Podsakoff, N., 2003. Common method biases in behavioral research: A critical review of the literature and recommended remedies. Journal of Applied Psychology 88 (5), 879-903.

Podsakoff, P.M., Organ, D.W., 1986. Self-reports in organizational research: Problems and prospects. Journal of Management 12 (4), 531-544.

Priem, R.L., Butler, J.E., 2001. Is the resource-based "view" a useful perspective for strategic management research? Academy of Management Review 26 (1), 57-66.

Rothaermel, F.T., Hill, C.W., 2005. Technological discontinuities and complementary assets: A longitudinal study of industry and firm performance. Organization Science 16, 52-70.

Russom, P., 2011. The three Vs of big data: TDWI Research: Best Practice Report, Fourth Quarter.

Sanders, N.R., 2014. Big Data Driven Supply Chain Management: A framework for implementing analytics and turning information into intelligence. Pearson Financial Times.

Schoenherr, T., Speier-Pero, C., 2015. Data science, predictive analytics, and big data in supply chain management: Current state and future potential. Journal of Business Logistics 36 (1), 120-132. 
Sousa, R., Voss, C., 2008. Contingency research in operations management practices. Journal of Operations Management 26 (6), 697-713.

Stank, T., Crum, M., Arango, M., 1999. Benefits of interfirm coordination in food industry supply chains. Journal of Business Logistics 20 (2), 21-41.

Stinchcombe, A.L., 1965. Social structure and organizations. In: March, J.G. (Ed.), Handbook of Organizations. Rand McNally, Chicago, 142-193.

Swink, M., Nair, A., 2007. Capturing the competitive advantages of AMT: Designmanufacturing integration as a complementary asset. Journal of Operations Management 25 (3), 736-754.

Tan, K.H., Zhan, Y., Ji, G., Ye, F., Chang, C., 2015. Harvesting big data to enhance supply chain innovation capabilities: An analytic infrastructure based on deduction graph. International Journal of Production Economics 165, 223-233.

Teece, D., 1986. Profiting from technological innovation: Implications for integration, collaboration, licensing, and public policy. Research Policy 15, 295-305.

Terjesen, S., Patel, P.C., Covin, J.G., 2011. Alliance diversity, environmental context and the value of manufacturing capabilities among new high technology ventures. Journal of Operations Management 29 (1-2), 105-115.

Waguih, I., 2017. Creating an innovation culture. McKinsey Quarterly 2017 Issue 4, 123-127.

Waller, M., Fawcett, S., 2013. Data science, predictive analytics, and big data: A revolution that will transform supply chain design and management. Journal of Business Logistics 34, 77-84.

Wernerfelt, B., 1984. A resource-based view of the firm. Strategic Management Journal 5 (2), 171-180.

Williams, L.J., Anderson, S.E., 1994. An alternative approach to method effects by using latentvariable models: Applications in organizational behaviour research. Journal of Applied Psychology 79 (3), 323-331.

Yoo, Y., Kim, K., 2015. How Samsung became a design powerhouse. Harvard Business Review 93 (9), 72-79.

Yu, W., 2015. The effect of IT-enabled supply chain integration on performance. Production Planning \& Control 26 (12), 945-957. 
Yu, W., Chavez, R., Jacobs, M.A., Feng, M., 2018. Data-driven supply chain capabilities and performance: A resource-based view. Transportation Research Part E: Logistics and Transportation Review 114, 371-385.

Yu, W., Jacobs, M.A., Salisbury, W.D., Enns, H., 2013. The effects of supply chain integration on customer satisfaction and financial performance: An organizational learning perspective. International Journal of Production Economics 146 (1), 346-358.

Zhang, H., 2016. How to revive China's manufacturing sector? China Daily, 20 December 2016. Available at: http://www.chinadaily.com.cn/opinion/2016-12/20/content_27716250.htm (accessed 8th June 2018).

Zhao, X., Flynn, B.B., Roth, A.V., 2006. Decision sciences research in China: A critical review and research agenda-foundations and overview. Decision Sciences 37 (4), 451-496.

Zhao, X., Huo, B., Selend, W., Yeung, J.H.Y., 2011. The impact of internal integration and relationship commitment on external integration. Journal of Operations Management 29, 17 32. 
Table 1: Demographic characteristics of respondents $(n=329)$

\begin{tabular}{|c|c|c|c|}
\hline & Percent (\%) & & Percent (\%) \\
\hline Industries & & Number of employees & \\
\hline Automobile & 34.3 & $1-100$ & 17.0 \\
\hline Chemicals and petrochemicals & 15.2 & $101-200$ & 10.9 \\
\hline Electronics and electrical & 7.9 & $201-500$ & 19.8 \\
\hline Fabricated metal product & 2.4 & $501-1000$ & 8.2 \\
\hline Food, beverage and alcohol & 2.7 & $1001-3000$ & 16.4 \\
\hline Rubber and plastics & 4.0 & $>3000$ & 27.7 \\
\hline Textiles and apparel & 33.4 & & \\
\hline Firm age (years) & & Firm ownership & \\
\hline$\leq 10$ & 31.3 & State-owned manufacturer & 32.8 \\
\hline $11-20$ & 31.6 & Private Chinese manufacturer & 39.5 \\
\hline $21-30$ & 10.6 & Wholly foreign-owned manufacturer & 10.9 \\
\hline$>30$ & 26.4 & Joint venture manufacturer & 16.7 \\
\hline Respondent location (geographical regions) & & Years in current position & \\
\hline Pearl River Delta* & 5.2 & $\leq 5$ & 41.3 \\
\hline Yangtze River Delta & 10.0 & $6-10$ & 30.7 \\
\hline Bohai Sea Economic Area & 6.6 & $>10$ & 28.0 \\
\hline Central China & 8.2 & & \\
\hline Southwest China & 69.9 & & \\
\hline
\end{tabular}

Note: ${ }^{*}$ It includes one firm in Taiwan and one firm in Hong Kong. 
Table 2: Reliability and validity analysis

\begin{tabular}{|c|c|c|c|c|c|}
\hline Measurement Items & $\begin{array}{l}\text { Factor } \\
\text { loadings }\end{array}$ & $\begin{array}{l}\text { t- } \\
\text { values }\end{array}$ & $\alpha$ & CR & AVE \\
\hline \multicolumn{3}{|l|}{ 1. Data-driven supply chain orientation (Sanders, 2014) } & 0.907 & 0.908 & 0.663 \\
\hline \multicolumn{6}{|l|}{$\begin{array}{l}\text { Establish a flexible and open central data environment } \\
\text { Build consistent interonerable cross-functional department databases to }\end{array}$} \\
\hline \multicolumn{6}{|l|}{$\begin{array}{l}\text { Build consistent interoperable, cross-functional department databases to } \\
\text { enable concurrent engineering, rapid experimentation and simulation, and } \\
\text { co-creation }\end{array}$} \\
\hline \multicolumn{6}{|l|}{ Aggregate customer data and make them widely available to improve service } \\
\hline $\begin{array}{l}\text { level, capture cross- and up-selling opportunities, and enable design-to- } \\
\text { value }\end{array}$ & 0.835 & 17.534 & & & \\
\hline $\begin{array}{l}\text { Implement advanced demand forecasting and supply planning across } \\
\text { suppliers }\end{array}$ & 0.811 & 16.833 & & & \\
\hline $\begin{array}{l}\text { Implement lean manufacturing and model production virtually (such as digital } \\
\text { factory) to create process transparency, develop dashboards, and visualize } \\
\text { bottlenecks }\end{array}$ & 0.754 & 15.227 & & & \\
\hline \multicolumn{3}{|l|}{ 2. Financial performance (Flynn et al., 2010) } & 0.941 & 0.946 & 0.815 \\
\hline Growth in sales & 0.739 & - & & & \\
\hline Growth in return on investment & 0.955 & 18.436 & & & \\
\hline Return on assets (ROA) & 0.931 & 17.911 & & & \\
\hline Growth in ROA & 0.966 & 18.663 & & & \\
\hline \multicolumn{3}{|l|}{ 3. Innovation focused complementary assets (Christmann, 2000) } & 0.879 & 0.886 & 0.667 \\
\hline \multicolumn{3}{|l|}{ We focus on being the first in the industry to try new methods and } & & & \\
\hline \multirow{2}{*}{$\begin{array}{l}\text { We focus on investing in new equipment and machinery } \\
\text { We have been leaders in introduction of product innovations over the last } 3 \\
\text { years }\end{array}$} & 0.652 & 11.075 & & & \\
\hline & 0.943 & 15.276 & & & \\
\hline $\begin{array}{l}\text { We have been leaders in introduction of process innovations over the last } 3 \\
\text { years }\end{array}$ & 0.946 & 15.299 & & & \\
\hline \multicolumn{6}{|c|}{ Model fit statistics: $X^{2}=183.870 ; \mathrm{df}=62 ; \chi^{2} / \mathrm{df}=2.966 ; \mathrm{RMSEA}=0.077 ; \mathrm{CFI}=0.967 ; \mathrm{IFI}=0.967 ; \mathrm{TLI}=0.958 ; \mathrm{SRMR}=0.046$} \\
\hline
\end{tabular}

Table 3: Descriptive statistics

\begin{tabular}{llllll}
\hline & Mean & S.D. & DDSCO & FP & CA-I \\
\hline Data-driven supply chain orientation (DDSCO) & 4.314 & 1.272 & $0.814^{\mathrm{a}}$ & & \\
Financial performance (FP) & 4.376 & 1.362 & $0.540^{* *}$ & 0.903 & \\
Innovation focused complementary assets (CA-I) & 4.402 & 1.378 & $0.507^{* *}$ & $0.444^{* *}$ & 0.817 \\
\hline
\end{tabular}

Note: a Square root of AVE is on the diagonal.

${ }^{* *}$ Correlation is significant at the 0.01 level (2-tailed). 
Table 4: Results of hypothesis testing

\begin{tabular}{|c|c|c|c|}
\hline & Model 1 & Model 2 & Model 3 \\
\hline \multicolumn{4}{|l|}{ Control variables } \\
\hline Firm age & $-0.006\left(-0.090^{a}, 1.792^{b}\right)$ & $0.013(0.222,1.820)$ & $0.016(0.268,1.821)$ \\
\hline Firm size & $0.052(0.802,1.627)$ & $-0.047(-0.826,1.709)$ & $-0.051(-0.899,1.711)$ \\
\hline Industry1 & $0.316(3.318,3.459)^{* \star *}$ & $0.235(2.876,3.499)^{* *}$ & $0.216(2.653,3.537)^{* t}$ \\
\hline Industry2 & $-0.113(-1.443,2.325)$ & $-0.056(-0.842,2.342)$ & $-0.051(-0.772,2.344)$ \\
\hline Industry3 & $0.115(1.680,1.789)^{\dagger}$ & $0.114(1.951,1.790)^{\dagger}$ & $0.112(1.924,1.790)^{\dagger}$ \\
\hline Industry4 & $0.139(1.522,3.178)$ & $0.179(2.304,3.185)^{*}$ & $0.167(2.157,3.201)^{*}$ \\
\hline Ownership1 & $0.037(0.456,2.564)$ & $0.026(0.370,2.579)$ & $0.025(0.366,2.579)$ \\
\hline Ownership2 & $0.087(1.062,2.564)$ & $0.084(1.198,2.564)$ & $0.084(1.209,2.564)$ \\
\hline Ownership3 & $0.106(1.612,1.646)$ & $0.060(1.073,1.670)$ & $0.059(1.046,1.670)$ \\
\hline Region1 & $0.077(0.684,4.849)$ & $0.069(0.716,4.876)$ & $0.067(0.696,4.876)$ \\
\hline Region2 & $0.097(1.143,2.744)$ & $0.040(0.549,2.804)$ & $0.043(0.591,2.805)$ \\
\hline Region3 & $0.114(1.464,2.326)$ & $0.029(0.437,2.368)$ & $0.023(0.346,2.372)$ \\
\hline Region4 & $0.205(2.367,2.849)^{*}$ & $0.152(2.056,2.862)^{*}$ & $0.152(2.080,2.862)^{*}$ \\
\hline \multicolumn{4}{|c|}{ Independent variables } \\
\hline DDSCO & & $0.405(7.404,1.577)^{\star \star \star}$ & $0.409(7.515,1.579)^{\star \star \star}$ \\
\hline CA-I (moderator) & & $0.189(3.590,1.467)^{\star \star *}$ & $0191(3.640,1.467)^{\star \star *}$ \\
\hline \multicolumn{4}{|l|}{ Interaction effect } \\
\hline DDSCO $\times$ CA-I & & & $0.097(2.187,1.041)^{*}$ \\
\hline$R^{2}$ & 0.174 & 0.405 & 0.414 \\
\hline Adjust $R^{2}$ & 0.140 & 0.377 & 0.384 \\
\hline$F$-value & $5.122^{\star * *}$ & $14.228^{* * *}$ & $13.798^{* \star \star}$ \\
\hline
\end{tabular}

${ }^{* * *} p<0.001 ;{ }^{* *} p<0.01 ;{ }^{*} p<0.05 ; \dagger p<0.10$.

Note: The numbers in parentheses are: a $t$ values and ${ }^{b}$ variance inflation factor (VIF); dependent variable is financial performance. 
Figure 1: Conceptual framework

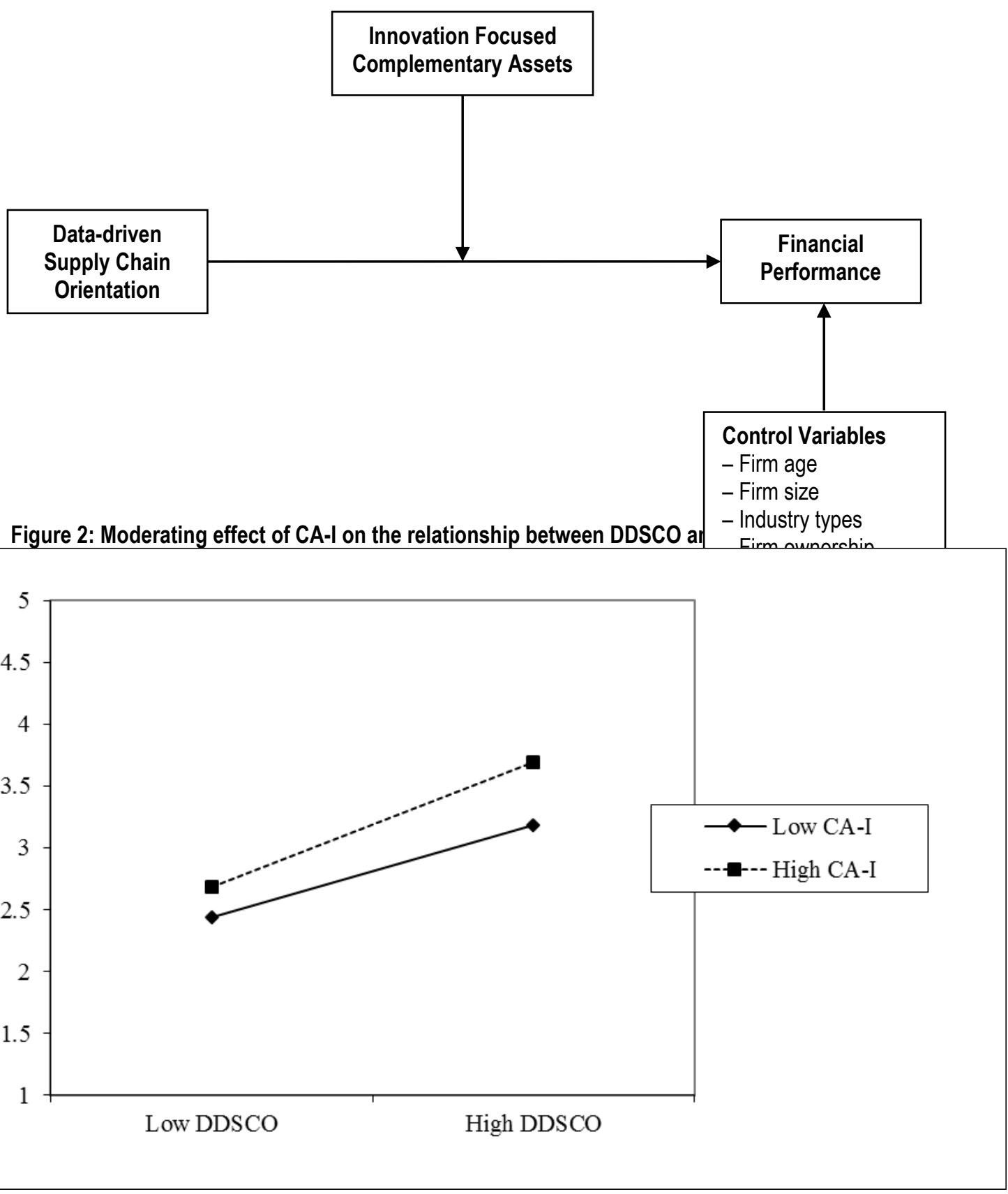

